\title{
Effect of a desensitizing dentifrice on the bond strength of different adhesive systems
}

\author{
Andrea Nóbrega Cavalcanti', Evangelista Santos de Souza², Gabriela dos Santos Lopes², \\ Anderson Pinheiro de Freitas ${ }^{3}$, Roberto Paulo Correia de Araújo ${ }^{4}$, Paula Mathias ${ }^{3}$
}

\begin{abstract}
${ }^{1}$ Area of Restorative Dentistry, School of Dentistry, School of Medicine and Public Health of Bahia (BAHIANA) and School of Dentistry, Federal University of Bahia (FOUFBA), Salvador, BA, Brazil

${ }^{2}$ Area of Restorative Dentistry, School of Dentistry, School of Medicine and Public Health of Bahia (BAHIANA), Salvador, BA, Brazil

${ }^{3}$ Area of Restorative Dentistry, School of Dentistry, Federal University of Bahia (FOUFBA), Salvador, BA, Brazil

${ }^{4}$ Area of Restorative Dentistry, Institute of Health Sciences, Federal University of Bahia (UFBA), Salvador, BA, Brazil
\end{abstract}

Received for publication: April 09, 2013 Accepted: June 25, 2013

Correspondence to: Andrea Nóbrega Cavalcanti Escola Bahiana de Medicina e Saúde Pública Curso de Odontologia

Avenida Silveira Martins, 3386

CEP: 41150-100 - Cabula, Salvador, BA, Brasil

Phone: +557132578200

E-mail: andreancavalcanti@yahoo.com.br

\section{Abstract}

Aim: This in vitro study evaluated the effect of using a dental hypersensitivity treatment on the bond strength to dentin of etch-and-rinse and self-etching simplified adhesive systems. Methods: 40 healthy molars were used. The crowns of teeth were removed at the dentinoenamel junction, and remaining roots were sectioned in the mesiodistal direction along their long axis, separating the buccal and lingual/palatal halves. The segments obtained were ground, keeping the buccal or lingual/palatal face turned downwards in order to flatten the surface and produce a standardized smear layer. Prepared specimens were randomly distributed into 4 groups $(n=10)$, according to the combination of surface treatment with the desensitizing dentifrice Colgate Sensitive Pro-Relief (Colgate Palmolive ${ }^{\circledR}$ ) (test group - with dentifrice and control group - without dentifrice) and type of simplified bonding agent (etch-and-rinse and self-etching agents). Resin composite blocks were fabricated on the dentin surfaces, after application of bonding agents, and specimens were sectioned into rectangular stick-shaped specimens with cross-sectional area of approximately $0.8 \mathrm{~mm}^{2}$. For microtensile bond strength tests, 4 sticks were randomly selected from the central region of specimens, and fixed to a universal test machine. Data were analyzed statistically by the Mann-Whitney $U$ test $(a=0.05)$. Results: The bond strength obtained in the group without desensitizer (control) + etch-and-rinse agent was significantly higher compared with the other groups. Under both experimental conditions, the self-etching agent showed weak bond strength to dentin. Conclusions: Change in the dentin substrate by obliteration of tubules in the process of relieving dentinal sensitivity could reduce the bond strength of simplified etch-and-rinse and self-etching bonding agents.

Keywords: dentin, dentin sensitivity, adhesive systems.

\section{Introduction}

Dentinal hypersensitivity is defined as a transitory pain arising from exposed dentin, typically in response to chemical, thermal, tactile or osmotic stimuli, which cannot be attributed to any other form of defect or dental pathology ${ }^{1}$. Many stimuli known to cause pain on the dentin surface cause the displacement of fluids inside the tubules, which is responsible for the increase in the mechanical stimulation of the dentinal nerve fibers, the A-fibers of the pulp wall ${ }^{2}$. This common 
clinical condition has a challenging treatment given its complex etiology ${ }^{3}$.

Brännström and Aström² (1964) observed absence or extensive reduction in the layer of odontoblasts below the exposed dentin in the presence of hypersensitivity, and formulated the hydrodynamic theory. This theory assumes that a stimulus applied on the dentin surface causes movement of the tubular fluid, which in turn activates mechanoreceptor nerves, causing pain and discomfort. Consequently, it is assumed that if the functional radius of open dentinal tubules diminishes, the permeability would also decrease, thereby reducing dentin sensitivity ${ }^{4}$.

Nonetheless, episodes of tooth hypersensitivity can also occur in the absence of exposed dentin. For this reason, complementary theories have been formulated in order to explain such condition. In a previous study, it was proposed that the pain was not due solely to hydrodynamic receptors that were sensitive to fluid flow inside dentin. Dentin deformation on pulp surface induced by thermal stimuli may also trigger nerve impulses ${ }^{5}$.

The diagnosis of dentinal hypersensitivity must associate the data of anamnesis with the clinical aspects, so that clinical situations with similar symptoms can be discarded. Currently, one of the main causes of dentin hypersensitivity is the presence of non-carious cervical lesions (NCCLs) ${ }^{6-7}$. Such lesions are characterized by the loss of tooth structure at the cementoenamel junction level, and are usually related to the combined effects of erosion, abrasion and abfraction (flexural stress) ${ }^{7}$.

The options for the treatment of hypersensitivity include both invasive and non-invasive procedures. Non-invasive treatment involves the application of topical agents and dentifrices that contain active desensitizing agents ${ }^{4,8-11}$. These are considered simple, low costing and efficient approaches as the first line of treatment for the majority of patients. Moreover, the use of different types of lasers in the treatment of dentin hypersensitivity has been reported, with wide variation in their effectiveness, depending on the used type of laser and parameters ${ }^{11-13}$. Invasive procedures may include gingival surgery, adhesive restoration or pulpectomy ${ }^{11}$.

The restoration of NCCL, especially the ones related to abfraction, is usually considered in order to prevent further progression, protect against pulp exposure and tooth fracture and improve aesthetics ${ }^{14}$. However, adhesive restorations placed at cervical regions are at a higher risk of failure due to continuous presence of abrasive, erosive and tensile stresses. Also, one still controversial question concerns the effectiveness of the adhesive procedure after performing desensitizing procedures with agents that obliterate dentin ${ }^{13}$.

It is known that the mechanisms of bonding to dentin vary according to the type of the used adhesive system ${ }^{11,15}$. In addition to different bonding mechanisms, etch-and-rinse and self-etching agents may also present variable effectiveness on dentin substrates, and there are reports that the latter are less affected by the regional variation in dentin ${ }^{16}$. Since desensitizing dentifrices may act modifying dental surfaces, the working hypothesis of the present study is that such surface modification would negatively impact on dentin bonding. Thus, the purpose of the present study was to evaluate the effect of the use of a hypersensitivity treatment on the bond strength to dentin of etch-and-rinse and selfetching simplified adhesive systems.

\section{Material and methods}

Forty sound third molars were obtained after the research project's approval by the instructional Ethics Committee (Protocol No. 153/10) and were stored in $0.1 \%$ thymol solution for use within 6 months of extraction.

The tooth crowns were removed at the cementoenamel junction using a double-faced flexible diamond disk (\#7020, KG Sorensen, Cotia, SP, Brazil) at low speed and under constant water cooling. The roots were sectioned in a mesiodistal direction along their long axes, separating the buccal and lingual/palatal halves. The segments obtained were ground wet onto abrasive papers grits \#400 and \#600 in a polishing machine (Aropol 2V, Arotec S.A Industria e Comércio, Cotia, SP, Brazil), keeping the buccal or lingual/ palatal face turned downwards in order to flatten the surface and produce a standardized smear layer.

The adhesive systems and desensitizing dentifrice selected for the study, their modes of use, compositions and manufacturers are described in Table 1. The prepared specimens were randomly distributed into 4 experimental groups $(n=10)$, according to the combination of surface treatment (without or with Colgate Sensitive Pro-Relief; control and test) and type of bonding agent used for restoration (etch-and-rinse/Adper Single Bond 2 and selfetching/GO):

Group 1: Without use of desensitizing agent (control) + Adper Single Bond 2

Group 2: Without use of desensitizing agent (control) $+\mathrm{GO}$

Group 3: Application of Sensitive Pro-Relief dentifrice (test) + Adper Single Bond 2

Group 4: Application of Sensitive Pro-Relief dentifrice (test) $+\mathrm{GO}$

\section{Application of desensitizing dentifrice}

The dentifrice was applied in the dentin surfaces of Groups 3 and 4, using a disposable applicator tip, with smooth, rubbing movements for $1 \mathrm{~min}$. After this period, surfaces were carefully washed with distilled water. The procedure was repeated twice a day with $12 \mathrm{~h}$ intervals, totaling 24 applications, simulating use for 12 days. After simulation of the desensitizing procedure, the specimens were stored in distilled water a $37^{\circ} \mathrm{C}$ for $24 \mathrm{~h}$, until the restoration process was performed.

During the time required to perform the desensitizing protocol in Groups 3 and 4 (12 days), the surfaces of control groups 1 and 2 were kept in distilled water at $37^{\circ} \mathrm{C}$ to standardize the water storage time of specimens in all groups. 
Table 1 - Technical information about the materials used for the study.

\begin{tabular}{|c|c|c|}
\hline Product & Composition & Application Mode \\
\hline $\begin{array}{l}\text { Colgate Sensitive Pro-Relief }{ }^{\top \mathrm{M}} \\
\text { Dentifrice (Colgate Palmolive } \circledast \text {, } \\
\text { Osasco, SP, Brazil) }\end{array}$ & $\begin{array}{l}\text { Calcium Carbonate, Water, Sorbitol, Arginine } \\
\text { Bicarbonate, Sodium Lauryl Sulphate, Sodium } \\
\text { Monofluorphosphate, Aroma, Cellulose Gum, } \\
\text { Bicarbonate of Soda, Acesulfame potassium, } \\
\text { Sodium Silicate, Xanthan Gum, Sucralose, Titanium } \\
\text { Dioxide, Active Ingredients: } 8 \% \text { Arginine, Sodium } \\
\text { Monofluorphosphate } 1.10 \% \text { ( } 1450 \mathrm{ppm} \text { of fluoride). }\end{array}$ & $\begin{array}{l}\text { Apply a small quantity of the product directly } \\
\text { on the sensitive tooth, massaging it for } 1 \\
\text { min, once a week or less frequently. } \\
\text { Eliminate after use. }\end{array}$ \\
\hline $\begin{array}{l}\text { Adper Single Bond } 2 \text { (3M ESPE, } \\
\text { St. Paul, MN, USA) }\end{array}$ & $\begin{array}{l}\text { Bis-GMA, HEMA, dimethacrylates, ethanol, water, } \\
\text { photoinitiator, methacrylate functional copolymer of } \\
\text { polyacrylic and poly(itaconic) acids, } 5 \mathrm{~nm} \text { colloidal } \\
\text { filler ( } 10 \% \text { by weight). }\end{array}$ & $\begin{array}{l}\text { 1) Dentin etching with } 37 \% \text { phosphoric acid } \\
\text { for } 15 \mathrm{~s} \text {; washing for } 15 \mathrm{~s} \text { and drying with } \\
\text { absorbent paper, keeping the surface wet; } \\
\text { 2) Application of the adhesive, } 2 \text { coats with } \\
\text { agitation for } 15 \mathrm{~s} \text {, removal of excess } \\
\text { solvent; } \\
\text { 3) Light activation for } 10 \mathrm{~s} \text {. }\end{array}$ \\
\hline $\begin{array}{l}\text { GO (SDI Limited, Bayswater, } \\
\text { Victoria, Australia) }\end{array}$ & $\begin{array}{l}\text { Phosphoric acid ester monomer; Dimethacrylate } \\
\text { monomer; Monomethacrylate monomer; Silicone } \\
\text { dioxide load; Water; Acetone; Photoinitiators; } \\
\text { Stabilizer; Sodium Fluoride }\end{array}$ & $\begin{array}{l}\text { 1) Clean the tooth; } \\
\text { 2) Remove excess } \mathrm{H}_{2} 0 \text { with absorbent } \\
\text { paper; } \\
\text { 3) Apply the adhesive, wait } 20 \mathrm{~s} \text {, dry with } \\
\text { paper for } 5 \mathrm{~s} \text {; } \\
\text { 4) Light activation for } 10 \mathrm{~s} \text {. }\end{array}$ \\
\hline
\end{tabular}

Abbreviations: HEMA =2-hydroxyethylmethacrylate; BIS-GMA = Bisphenol-glycidyl-methacrylate

\section{Restorative procedure}

In the four groups, the adhesive systems were applied according to the protocol recommended by the manufacturers (Table 1). After the respective adhesive procedures, a resin composite block (5x5x4 mm) (Filtek ${ }^{\mathrm{TM}}$ Z250, 3M ESPE, St. Paul, MN, USA) was constructed on dentin surfaces. The resin composite was applied in $2 \mathrm{~mm}$ horizontal increments, each one light activated for $40 \mathrm{~s}$.

\section{Microtensile bond strength test}

Twenty-four hours after the adhesive procedures, each specimen was taken to a precision sectioning machine (Elsaw, ElQuip, São Carlos, SP, Brazil), with a diamond disc, and sections were obtained at $1.2 \mathrm{~mm}$ intervals ,perpendicular to the bonded interface. Thus, rectangular stick-shaped specimens were obtained, with a cross-sectional area of approximately $0.8 \mathrm{~mm}^{2}$. The section area of each specimen was measured with a digital caliper after fracture in order to calculate the bond strength. The sticks were stored in distilled water until the moment of the bond strength test.

For the microtensile test, four sticks from the center of each specimen were randomly selected. Using a cyanoacrylate esterbased adhesive (Loctite ${ }^{\circledR}$ Super Bonder ${ }^{\circledR}$ Flex Gel; Henkel Ltda, Itapevi, SP, Brazil), the specimens were fixed to the microtensile appliance, which was coupled to a universal test machine (EMIC DL 10000, EMIC Equipamentos e Sistemas de Ensaio Ltda, São José dos Pinhais, PR, Brazil). The tensile load was applied perpendicular to the bond interface at a crosshead speed of 0.5 $\mathrm{mm} / \mathrm{min}$ until the bond rupture. The values expressed by the machine in $\mathrm{kgf}$ were converted into $\mathrm{MPa}$.

\section{Statistical analysis}

Premature failures during specimen preparation for the microtensile test were considered to be zero $\mathrm{MPa}$ in order to avoid overestimating bond strength values. After an exploratory analysis for data homoscedasticity and normality, results were subjected to non-parametric analysis, using the Mann-Whitney test for comparison between the main factors: surface treatment with the desensitizing agent and type of adhesive system. Nonparametric analyses were made since the data did not fullfil the criteria for parametric tests. Statistical analysis was performed using the BioEstat software, version 5.0 program, at a significance level of 5\%.

\section{Results}

In the group in which dentifrice was applied and the restoration was made using the adhesive GO, all specimens were lost due to early failure. The results of the microtensile bond strength test in the groups are presented in Table 2 .

According to the statistical analysis, the bond strength obtained with the etch-and-rinse agent Single Bond 2 was significantly higher compared with the selfetching system GO, under both control $(p=0.002)$ and test conditions $(p=0.04)$. For both adhesive systems there was significant difference between the experimental conditions, with the lowest bond strength values found in the test condition (Adper Single Bond $2-p=0.04 /$ $\mathrm{GO}-\mathrm{p}=0.002)$. 
Table 2 - Mean values of microtensile bond strength (MPa) in the experimental groups

\begin{tabular}{lcc}
\hline Surface treatment & \multicolumn{2}{c}{ Adhesive system } \\
& Adper Single Bond 2 & GO \\
\hline Control (no treatment) & $20.2 \mathrm{Aa}$ & $5.2 \mathrm{Ab}$ \\
Test (dentifrice) & $9.1 \mathrm{Ba}$ & $0.0 \mathrm{Bb}$
\end{tabular}

Different letters represent statistically significant differences (Mann-Whitney; $a=0.05$ ). Uppercase letters compare surface treatments for each adhesive, and lowercase letters compare adhesive for each surface treatment.

\section{Discussion}

Dentinal tubule sealing with desensitizing agents that act by obliterating the tubules, before the use of adhesive materials, may be an important preventive method for the relief of dentin sensitivity, indicated for hypersensitive regions with loss of dental structure and needing restoration, such as some NCCLs. However, there have been reports that the desensitizing agents may make it difficult for the adhesive system to infiltrate, and consequently hybridize the dentin, leading to lower bond strength, and contributing to gaps at the bonded interface in the areas of stress ${ }^{13,17}$.

The agent used in this study (Colgate Sensitive Pro-Relief) induces the formation of a biological material in which arginine is combined with calcium carbonate. This association between arginine and calcium provides an alkaline environment that encourages endogenous calcium and phosphate ion deposition and occludes the dentinal tubules ${ }^{10}$.

In the present study, the working hypothesis was that the change in dentin promoted by the desensitizing agent would result in variations in the effectiveness of simplified adhesive systems. According to the obtained results, it was verified that both the etch-and-rinse and self-etching system presented lower bond strength when the dentin surface was changed by the use of desensitizing dentifrice.

Another study ${ }^{13}$ analyzed the influence of other desensitization procedures (HEMA/glutaraldehyde, potassium oxalate and low level laser therapy) on the bond strength to dentin. According to the authors, the specimens treated with dentin desensitizers presented significantly lower bond strength than the non-treated specimens, with the exception of those treated with the HEMA/glutaraldehyde-based agent.

The tubular occlusion produced by the biological material containing arginine and calcium carbonate might be a reason for the lower bond strength found in the test groups of the present study. This tubular occlusion was verified in a previous study ${ }^{10}$, which, by electronic spectroscopy, observed arginine inside the occluded dentinal tubule. In addition, the interference of desensitizing agents in bond strength to dentin may occur as a result of the neutralization of acid etching by the deposits formed on the treated substrate, consequently inhibiting the formation of an efficient and uniform hybrid layer ${ }^{18}$.

In this study, the hypothesis that simplified agents of the etch-and-rinse and self-etching type acted in a distinct manner on the dentin substrate either treated or not with desensitizing dentifrice was also tested. A previous study indicated that adhesive systems that use previous acid etching are apparently more sensitive to the regional differences in dentin than the self-etching ones ${ }^{16}$. However, according to the results obtained in this study, the etch-and-rinse agent presented significantly higher bond strength than the selfetching system under both experimental conditions. These findings agree with the ones of a recent clinical trial ${ }^{6}$, in which authors tested the use of different adhesive systems to restore NCCLs. According to their evaluation, restorations placed with the use of an etch-and-rinse agent showed higher retention rates than the ones placed with an all-in-one adhesive system.

Removal of the smear layer and opening of the dentinal tubules by means of complete acid etching allow free diffusion of the adhesive agents and may contribute to the bond effectiveness of etch-and-rinse adhesive systems. This mechanism, added to the characteristics of the simplified etch-and-rinse adhesive used in this study, may justify its higher bond strength under both experimental conditions. The Adper Single Bond 2 adhesive system has $10 \%$ of filler nanoparticles by weight in its composition. According to a previous study, the presence of fillers may be important to strengthen the adhesive layer and to guarantee an adequate thickness over the hybrid layer, protecting it against stresses ${ }^{19}$. Nevertheless, it is important to point out that this type of bond mechanism may increase the potential for dentin sensitivity and pulp irritation if perfect dentin sealing does not occur in the previously etched area ${ }^{20}$.

Shirai et al. ${ }^{21}$, compared versions of simplified adhesive systems in different cavity configurations submitted to aging. According to the authors, under all the evaluated experimental conditions, the simplified self-etching system had lower bond strength than the others. This result may be justified in various ways. For example, the inhibition of composite polymerization by the acidity of this type of adhesive system; incomplete wetting; thickness of the adhesive layer; phase separation between the hydrophilic and hydrophobic components and greater sensitivity to hydrolysis ${ }^{15,19,21}$.

Considering the lower bond strength and greater number of premature failures obtained with the simplified self-etching system, it could also be speculated that the greater deposition of minerals promoted by the application of the desensitizing agent may have diminished the adhesiveness of the substrate to these types of bonding agents, as occurs in areas of tooth enamel and of hypermineralized dentin at NCCLs ${ }^{6,22-23}$. Sudies on the use of self-etching agents on enamel indicated the need for acid etching before the application of these adhesive systems; and some manufacturers have now included this modification of technique in their instructions for use. Thus, further studies are required in order to define protocols for the use of self-etching systems on substrates treated with desensitizing agents that act by occluding the tubules or increasing the deposition of minerals.

The findings of the present study demonstrated that as occurs with the variability of dentin inside the cavities due to the presence of different types of substrates (i.e., dentin sclerosis), the modification of dentin by desensitizing agents might interfere negatively on the performance of adhesive systems. Currently, according to the limitations of the present 
investigation, etch-and-rinse systems seem to be the best strategy to achieve adequate adhesive restorations, when dentin substrates have been changed by desensitizing agents. It is known that an ideal bonding agent should be effective irrespective of the regional characteristics of the structure of dentin. However, while such an agent is not developed, it is mandatory to know the morphophysiology of the tissues to be bonded, and the types of bond mechanism systems available in the market in order to obtain results with greater reliability and durability.

\section{References}

1. Addy M, Pearce N. Aetiological, predisposing and environmental factors in dentine hypersensitivity. Arch Oral Biol. 1994; 39: 33S-8S.

2. Brannstrom M, Astrom A. A study on the mechanism of pain elicited from the dentin. J Dent Res. 1964; 43: 619-25.

3. Sales-Peres SH, Carvalho FN, Marsicano JA, Mattos MC, Pereira JC, Forim MR et al. Effect of propolis gel on the in vitro reduction of dentin permeability. J Appl Oral Sci. 2011; 19: 318-23.

4. Arrais CAG, Chan DCN, Giannini M. Effects of desensitizing agents on dentinal tubule occlusion. J Appl Oral Sci. 2004; 12: 144-8.

5. Linsuwanont $\mathrm{P}$, Versluis A, Palamara JE, Messer HH. Thermal stimulation causes tooth deformation: a possible alternative to the hydrodynamic theory? Arch Oral Biol. 2008; 53: 261-72.

6. Tuncer D, Yazici AR, Özgünaltay G, Dayangac B. Clinical evaluation of different adhesives used in the restoration of non-carious cervical lesions: 24-month results. Aust Dent J. 2013; 58: 94-100.

7. Que K, Guo B, Jia Z, Chen Z, Yang J, Gao P. A cross-sectional study: non-carious cervical lesions, cervical dentine hypersensitivity and related risk factors. J Oral Rehabil. 2013; 40: 24-32.

8. Cummins D. Recent advances in dentin hypersensitivity: Clinically proven treatments for instant and lasting sensitivity relief. Am J Dent. 2010; 23: 3-13.

9. Ishihata H, Finger WJ, Kanehira M, Shimauchi H, Komatsu M. In vitro dentin permeability after application of Gluma $®$ desensitizer as aqueous solution or aqueous fumed silica dispersion. J Appl Oral Sci. 2011; 19: 147-53.

10. Lavender SA, Petrou I, Heu R, Stranick MA, Cummins D, KilpatrickLiverman $\mathrm{L}$, et al. Mode of action studies on a new desensitizing dentifrice containing $8.0 \%$ arginine, a high cleaning calcium carbonate system and 1450 ppm fluoride. Am J Dent. 2010; 23: 14-9.

11. Walters PA. Dentinal Hypersensitivity: A Review. J Contemp Dent Pract. 2005; 6: 107-17.

12. Oda M, Oliveira DC, Liberti EA. Avaliação morfológica da união entre adesivo/resina composta e dentina irradiada com laser Er: YAG e laser Nd: YAG: estudo comparativo por microscopia de varredura. Pesqui Odontol Bras. 2001; 15: 283-9.

13. Aranha ACC, Siqueira Junior CADS, Cavalcante LMA, Pimenta LAF, Marchi GM. Microtensile bond strengths of composite to dentin treated with desensitizer products. J Adhes Dent. 2006; 8: 85-90.

14. Romeed SA, Malik R, Dunne SM. Stress analysis of occlusal forces in canine teeth and their role in the development of non-carious cervical lesions: abfraction. Int J Dent. 2012; 2012: 234845. doi: 10.1155/2012/ 234845.

15. Silva e Souza Jr MH, Carneiro KG, Lobato MF, Silva e Souza P de A, de Góes MF. Adhesive systems: important aspects related to their composition and clinical use. J Appl Oral Sci. 2010; 18: 207-14.

16. Pereira PN, Okuda M, Sano H, Yoshikawa T, Burrow MF, Tagami J. Effect of intrinsic wetness and regional difference on dentin bond strength. Dent Mater. 1999; 15: 46-53.

17. Awang RAR, Masudi SM, Mohd Nor WZW. Effect of desensitizing agent on shear bond strength of an adhesive system. Arch Orofac Sci. 2007; $2: 32-5$
18. Pashley DH, Carvalho RM, Pereira JC, Villanueva R, Tay FR. The use of oxalate to reduce dentin permeability under adhesive restorations. Am J Dent. 2001; 14: 89-94.

19. Cavalcanti AN, Mitsui FHO, Ambrosano GMB, Mathias P, Marchi GM. Dentin bonding on different walls of a class II preparation. J Adhes Dent. 2008; 10: 17-23.

20. Pashley DH, Ciucchi B, Sano H, Horner JA. Permeability of dentin to adhesive agents. Quintessence Int. 1993; 24: 618-31.

21. Shirai K, De Munck J, Yoshida Y, Inoue S, Lambrechts P, Suzuki K, et al. Effect of cavity configuration and aging on the bonding effectiveness of six adhesives to dentin. Dent Mater J. 2005; 21: 110-24.

22. Cardoso MV, Neves AA, Mine A, Coutinho E, Landuyt KV, De Munck J, et al. Current aspects on bonding effectiveness and stability in adhesive dentistry. Aust Dent J. 2011; 56: 31-44.

23. De Munck J, Van Meerbeek B, Satoshi I, Vargas M, Yoshida Y, Armstrong $S$, et al. Microtensile bond strengths of one- and two-step self-etch adhesives to bur-cut enamel and dentin. Am J Dent. 2003; 16: 414-20. 